\title{
MicroRNA-27a-3p Reverses Adriamycin Resistance by Targeting BTG2 and Activating PI3K/Akt Pathway in Breast Cancer Cells
}

This article was published in the following Dove Press journal: OncoTargets and Therapy

\author{
Bei Zhu ${ }^{1,2}$ \\ Weixian Chen $\mathbb{D D}^{2}$ \\ Yue $\mathrm{Fu}^{2}$ \\ Xiaohan Cui ${ }^{1}$ \\ Lei Jin ${ }^{2}$ \\ Jiadeng Chao ${ }^{2}$ \\ Xiao Yun ${ }^{1,2}$ \\ Peng Gao ${ }^{2,3}$ \\ Shiting Shan ${ }^{1,2}$ \\ Jun $\mathrm{Li}^{2,3}$ \\ Xu Yin ${ }^{1,2}$ \\ Chunfu Zhu ${ }^{2}$ \\ Xihu Qin ${ }^{2}$
}

'Nanjing Medical University, Nanjing 210029 , People's Republic of China; ${ }^{2}$ Department of General Surgery, The Affiliated Changzhou No.2 People's Hospital of Nanjing Medical University, Changzhou 213000, People's Republic of China; ${ }^{3}$ Dalian Medical University, Dalian 1 16023, People's Republic of China
Correspondence: Chunfu Zhu; Xihu Qin Email zcfmlm@I63.com; zcfmlm@njmu. edu.cn

\begin{abstract}
Aim: This study aimed to explore the regulative mechanisms of miR-27a-3p in chemoresistance of breast cancer cells.

Materials and Methods: qRT-PCR was employed to determine miR-27a-3p expression in two breast cancer cell lines, MCF-7 and MCF-7/adriamycin-resistant cell line (MCF-7/ADR). The two cell lines were treated with miR-27a-3p mimics or inhibitors or corresponding negative control (NC), respectively. The changes were investigated by qRT-PCR, CCK-8 assay, Western blot (WB), colony formation assay, and flow cytometry assay. Moreover, luciferase reporter assay was analyzed to verify the downstream target gene of miR-27a-3p. Further investigation in the correlation between miR-27a-3p and BTG2 was launched by WB, flow cytometry assay, and CCK-8 assay. The expression of Akt and p-Akt was detected by WB.

Key Findings: Significantly higher miR-27a-3p expression was confirmed in MCF-7/ADR as compared with sensitive cell line MCF-7 $(P<0.05)$. The down-regulation of miR-27a-3p in MCF-7/ADR enhanced the sensitivity of cancer cells to adriamycin treatment, decreased multidrug resistance gene 1/P-glycoprotein (MDR1/P-gp) expression, enhanced the apoptosis-related proteins expression, increased adriamycin-induced apoptosis, and inhibited cell proliferation as compared to NC groups $(P<0.05)$. The up-regulation of miR-27a-3p in MCF7 showed the opposite results. BTG2 is identified as a direct target of miR-27a-3p and its down-regulation reversed ADR-resistance. BTG2 treatment exhibited inhibitory effect on $\mathrm{PI} 3 \mathrm{~K} /$ Akt pathway in MCF-7/ADR cells.
\end{abstract}

Significance: miR-27a-3p might be associated with resistance of breast cancer cells to adriamycin treatments, modulating cell proliferation and apoptosis by targeting BTG2 and promoting the PI3K/Akt pathway in breast cancer cells. miR-27a-3p/BTG2 axis might be a potential therapeutic target for clinical $\mathrm{BC}$ resistance.

Keywords: miR-27a-3p, chemoresistance, breast cancer, adriamycin, BTG2

\section{Introduction}

Breast cancer $(\mathrm{BC})$ is one of the most common malignancies worldwide, accounting for $15 \%$ of cancer deaths in women. ${ }^{1}$ Chemotherapy plays an important role in reducing mortality and suppressing recurrence in many patients with $\mathrm{BC}^{2}{ }^{2}$ Adriamycin (ADR), an anthracycline chemotherapeutic compound, has been widely used in a variety of cancers for more than 30 years. At present, this agent is considered one of the most effective components of adjunctive and palliative therapy for $\mathrm{BC}^{3}$ As an antineoplastic antibiotic, ADR damages DNA and induces reactive oxygen species (ROS) formation via intercalation into DNA and inhibition 
of topoisomerases I and II, thereby interfering with cell replication and activating apoptosis. ${ }^{4}$ Treatment with ADR has been found to contribute to prolonged survival time and improved overall survival in patients with various malignancies, including $\mathrm{BC}^{5}$ However, chemoresistance to ADR can occur, presenting a major clinical obstacle to improved prognosis in patients with $\mathrm{BC}{ }^{6}$ To enhance the efficacy of ADR-based chemotherapy, researchers must elucidate the molecular basis of the resistance mechanism and then develop a new therapeutic strategy to reverse this resistance.

MicroRNAs (miRNAs) are small, noncoding RNAs (20-22 bp) that regulate gene expression via posttranscriptional repression or degradation. ${ }^{7}$ Recent reports have shown that miRNAs contribute to the tumor processes of cell proliferation, apoptosis, migration, and invasion. ${ }^{8-10}$ A miRNA of special interest is miR-27a-3p, which is located on chromosome $19 .{ }^{11}$ MiR-27a-3p is considered an oncogene because its overexpression is associated with a poor prognosis, as observed in patients with osteosarcoma or gastric cancer. ${ }^{12,13}$ Some reports have found that miR-27a$3 p$ enhances colon cancer progression and differentiation. ${ }^{14}$ Besides, miR-27a-3p has been demonstrated to mediate chemoresistance of cancers such as leukemia, ovarian cancer, and hepatocellular carcinoma. ${ }^{15-17}$ In $\mathrm{BC}$, miR-27a-3p has been found to regulate cancer cell growth, proliferation, migration, invasion, and angiogenesis. ${ }^{18,19}$ Studies have also found that miR-27a-3p is involved in the sensitivity of $\mathrm{BC}$ to radiotherapy, ${ }^{20}$ endocrine therapy, ${ }^{21}$ and cisplatin therapy. ${ }^{22}$ However, few studies have assessed the relationship between miR-27a-3p and ADR resistance in BC.

B-cell translocation gene 2 (BTG2), also known as NGFinducible protein PC3/TIS21, belongs to the BTG/TOB gene family. ${ }^{23}$ The first identified member in the anti-proliferative gene family, BTG2 is believed to exhibit anticancer effects in many types of malignancies, including BC. ${ }^{24-26}$ Studies have demonstrated that BTG2 expression is down-regulated in $\mathrm{BC}$, and there is evidence that BTG2 is involved in the incidence, progression, metastasis, and prognosis of BC. ${ }^{26,27}$ Recently, the potential relationship between miRNAs and BTG2 has attracted attention, since one study discovered that 3 miRNAs (miR-21, miR-23a, and miR-27a) acted as cooperative repressors of some tumor suppressor genes in pancreatic ductal adenocarcinoma. ${ }^{28}$ However, the specific relationship between $\mathrm{BTG} 2$ and miR-27a-3p in BC remains unknown.

According to the above researches, this research was designed to investigate the potential role of miR-27a-3p/
BTG2 axis in the regulation of BC chemoresistance. This study will shed light on new strategies for clinical BC chemoresistance.

\section{Materials and Methods Cell Lines and Cell Cultures}

The human chemosensitive BC cell line MCF-7 was obtained from the American Type Culture Collection, and the ADR-resistant cell line MCF-7/ADR was purchased from Xinyu Biotechnology (XY-h268, Shanghai, China). Cells were cultured in Roswell Park Memorial Institute1640 medium (Gibco, Grand Island, NY, USA) supplemented with 10\% fetal bovine serum (Gibco, Lofer, Austria) at $37^{\circ} \mathrm{C}$ in a humidified atmosphere of $5 \% \mathrm{CO}_{2}$. To maintain the drug-resistant phenotype, ADR $(0.5 \mu \mathrm{g} / \mathrm{mL}$; Xinyu Biotechnology) was added to the culture medium of MCF7/ADR. The medium was replaced every 1 to 2 days.

Information of the two cell lines is as follows: i) MCF7 was estrogen receptor (ER)-positive breast cancer cells, the cells were derived from pleural effusion from a 69-year -old white women with breast cancer; ii) MCF-7/ADR was gradually induced as supplier from MCF-7 cells by using a certain concentration of adriamycin and STR data of cells were supplied in supplementary material (Figure S1 and 2). All cell lines were routinely tested for mycoplasma contamination and confirmed to be negative.

\section{Chemicals and Antibodies}

The polyclonal anti-Bcl-2, anti-Bcl-2 associated X (Bax), and anti-BTG2/PC3 antibodies were purchased from Abcam (Cambridge, MA, USA). The monoclonal anti- $\beta$ actin antibody was purchased from Paiwei Bio (Nanjing, China). The monoclonal anti-total Akt (Akt); anti-phospho -Akt (p-Akt); anti-Caspase3; anti-Cleaved-caspase3; antimultidrug resistance protein 1 (MDR1)/ABCB1 antibody; and anti-rabbit IgG, HRP-linked antibody were purchased from Cell Signaling Technology (Beverly, MA, USA).

\section{Cell Transfection}

Specific concentrations of mimics or inhibitors of miR-27a$3 p$ (RiboBio, Guangzhou, China) were transfected into cell cultures using the transfection reagent (RiboBio) to activate or inactivate miR-27a-3p expression, respectively. Negative controls (NC) were used for both reactions (see the RNA oligo sequences in Table 1). At $48 \mathrm{~h}$ after transfection, the transfection solution was replaced with complete culture medium. For RNA extraction and protein isolation, cells 
Table I RNA Oligo Sequences

\begin{tabular}{|l|l|}
\hline Name & Oligo Sequences \\
\hline hsa-miR-27a-3p mimics & $\begin{array}{l}\text { 5'-UUCACAGUGGCUAAGUUCCGC-3' } \\
\text { 5'-GGAACUUAGCCACUGUGAAUU-3' }\end{array}$ \\
\hline Mimic NC & $\begin{array}{l}\text { 5'-UUUGUACUACACAAAAGUACUG-3' } \\
\text { 5'-CAGUACUUUUGUGUAGUACAAA-3' }\end{array}$ \\
\hline $\begin{array}{l}\text { hsa-miR-27a-3p } \\
\text { inhibitors }\end{array}$ & 5'-GCGGAACUUAGCCACUGUGAA-3' \\
\hline
\end{tabular}

Abbreviation: NC, negative control.

were treated for $48 \mathrm{~h}$ according to the manufacturer's recommendations and were then harvested. The miRNA transfection efficiencies were determined by real-time polymerase chain reaction (PCR). The BTG2 DNA sequence and double-stranded siRNA against BTG2 (Genepharma, Shanghai, China) were then transfected into the MCF-7 and MCF-7/ ADR cells using the transfection reagent, respectively.

\section{Quantitative RT-PCR (qRT-PCR) Analysis}

Total RNA was extracted from MCF-7 and MCF-7/ADR cells using a Total RNA TriPure Isolation Reagent Kit (BioTeke, Beijing, China). The cDNA was obtained by reverse transcription using a PrimeScript RT Reagent Kit with gDNA Eraser (RR047A; Takara Bio Inc, Dalian, China). The bulge-loop miRNA qRT-PCR primer sets (one RT primer and a pair of qPCR primers for each set) specific for miR-27a-3p were designed by RiboBio. The qRT-PCR was performed with an AceQ qPCR SYBR Green Master Mix Kit (Q131-02; Vazyme Biotech, Nanjing, China) in an ABI 7500 RT-PCR system (Applied Biosystems, Foster City, CA, USA) using the following parameters: 1 cycle of predenaturation at $95^{\circ} \mathrm{C}$ for $10 \mathrm{~min}$, followed by 40 cycles at $95^{\circ} \mathrm{C}$ for $2 \mathrm{sec}, 60^{\circ} \mathrm{C}$ for $20 \mathrm{sec}$, and $70^{\circ} \mathrm{C}$ for $10 \mathrm{sec}$. At this point, miRNA expression was normalized to $\mathrm{U} 6$ and the relative fold changes were calculated using the $2^{-\Delta \Delta \mathrm{Ct}}$ method. Each sample was run independently in triplicate.

For mRNA expression analysis, total cellular RNA was isolated and reverse transcribed to cDNA. RT-PCR amplification was performed using the AceQ qPCR SYBR Green Master Mix Kit, and U6 was measured as an internal reference. The primers of mRNA and U6 were purchased from RiboBio (see the primer sequences in Table 2). The PCR reaction contained $2 \mu \mathrm{L}$ RT product, $10 \mu \mathrm{L} 2 \mathrm{X}$ SYBR Green Mix, $0.8 \mu \mathrm{L}$ forward primer and $0.8 \mu \mathrm{L}$ reverse primer ( $5 \mu \mathrm{M} / 1$ each), and nuclease-free water in a final volume of $20 \mu \mathrm{L}$. Standard PCR samples were analyzed using the ABI
Table 2 Primer Sequences for qRT-PCR

\begin{tabular}{|l|l|}
\hline Gene & Sequences \\
\hline U6 & $\begin{array}{l}\text { Forward 5'-GCTTCGGCAGCACATATA-3' } \\
\text { Reverse 5'-CGCTTCACGAATTTGCG-3' }\end{array}$ \\
\hline BTG2 & $\begin{array}{l}\text { Forward 5'-AACTGTTGCGTGCTTGAGTCTG-3' } \\
\text { Reverse 5'-CAGTTGCTAACCTTGCTTGCTC-3' }\end{array}$ \\
\hline
\end{tabular}

7500 RT-PCR system, and all qRT-PCR reactions were performed in triplicate. The expression levels of the target genes were again normalized to $\mathrm{U} 6$ and calculated using the $2^{-\Delta \Delta \mathrm{Ct}}$ method. The qRT-PCR was carried out at least 3 times.

\section{Western Blot Assay}

Cells were collected and lysed in RIPA lysis buffer on ice for $15 \mathrm{~min}$. After the samples underwent centrifugation at $12,000 \times \mathrm{g}$ for $10 \mathrm{~min}$ at $4^{\circ} \mathrm{C}$, the protein concentrations were determined using a BCA reagent (Beyotime, Beijing, China). Equal amounts of protein were then subjected to $10 \%$ or $15 \%$ sodium dodecyl sulfate polyacrylamide gel electrophoresis and transferred to polyvinylidene fluoride membranes (Millipore Corp., Bedford, MA, USA). After being blocked with $5 \%$ fat-free milk at room temperature $\left(37^{\circ} \mathrm{C}\right)$ for $2 \mathrm{~h}$, the membranes were incubated with primary antibodies against MDR1 (1:1250 dilution), Caspase3 (1:1000 dilution), Cleaved-caspase3 (1:1000 dilution), Bcl2 (1:1000 dilution), Bax (1:1000 dilution), BTG2 (1:1000 dilution), Akt (1:1000 dilution), p-Akt (1:2000 dilution), and $\beta$-actin (1:1000 dilution) at $4^{\circ} \mathrm{C}$ overnight. The protein levels were normalized to $\beta$-actin. The blots were then labeled with anti-rabbit IgG secondary antibody (1:3000 dilution) for 1 $h$ at $37^{\circ} \mathrm{C}$. Protein bands were detected using an enhanced chemiluminescence reagent (Thermo Fisher Scientific, Waltham, MA, USA). All Western blot experiments were repeated at least 3 times.

\section{Proliferation Assay}

A cell counting kit-8 (CCK-8) assay (Dojindo Company, Shanghai, China) was performed to evaluate the cells' sensitivity to the drug in triplication experiments. Briefly, cells $(8 \times$ $10^{3}$ ) were plated in 96-well microplates and incubated overnight. To calculate the IC50 values for ADR, MCF-7 cells were transfected with $0,0.22,0.45,0.90,1.80,3.60,7.19$, $14.38,28.75$, or $57.50 \mu \mathrm{M} / 1$ of ADR, and MCF-7/ADR cells were treated with $0,3.60,7.19,14.38,28.75,57.50,115.00$, or $230.00 \mu \mathrm{M} / 1$ of ADR for $48 \mathrm{~h}$. After treatment, the medium was replaced with $110 \mu \mathrm{L}$ culture medium containing $10 \mu \mathrm{L}$ 
CCK-8, and the cells were incubated for $3 \mathrm{~h}$. Finally, the absorbance was measured at $450 \mathrm{~nm}$ (OD450) using an ELISA plate reader (Bio-Tek, Winooski, Vermont, USA). The IC50 values were calculated using Graphpad Prism 7.00 (GraphPad Software, San Diego, CA, USA).

\section{Colony Formation Assay}

Cell colony formation was measured with a plate colony formation assay. MCF-7 cells were treated with the miR$27 \mathrm{a}-3 \mathrm{p}$ mimics or with the mimic $\mathrm{NC}$ for $48 \mathrm{~h}$ and then seeded in 6-well plates at 1000 cells per well. MCF-7/ ADR cells were treated with the miR-27a-3p inhibitors or with the inhibitor $\mathrm{NC}$ for $48 \mathrm{~h}$ and then seeded in 6-well plates at 800 cells per well. After 7 to 10 days, colonies were obviously formed with both cell types. The plates were then gently washed and stained with crystal violet. The number of colonies was counted by observing the proliferation of a single cell. Each assay was performed in triplicate on two separate occasions.

\section{Flow Cytometry Assay}

MCF-7 and MCF-7/ADR cells were seeded into 6-well plates and then treated with transfection for $48 \mathrm{~h}$. After 48 $\mathrm{h}$, the cells were washed twice with phosphate-buffered solution (PBS), stained for $15 \mathrm{~min}$ with the annexin V-FITC/PI Apoptosis Detection Kit (BD, Becton Dickinson Company, NJ, USA), and then collected. Samples were analyzed using FACSCanto TM II flow cytometry (Becton, Dickinson and Company). Triplicate experiments were performed for flow cytometry analysis.

\section{Databases and Bioinformatics}

To define the potential targets of miR-27a-3p, the miRNA targets predicted by publicly available computational algorithms were analyzed using miRWalk (http://mirwalk.umm. uni-heidelberg.de/human/mirna/46/), TargetScan (http:// www.targetscan.org/cgi-bin/targetscan/vert 72/targetscan. cgi? species $=$ Human\&gid $=\&$ mir_sc $=\&$ mir_c $=\&$ mir_nc $=$ $\underline{\text { \&mir_vnc }=\& m i r g=m i R-27 a-3 p})$, PicTar (https://pictar.mdcberlin.de/cgi-bin/PicTar vertebrate.cgi), and StarBase v3.0 (http://starbase.sysu.edu.cn/).

\section{Dual-Luciferase Reporter Assay}

The wild type (WT) and mutant (MUT) 3'UTR of BTG2 predicted binding sequences with $\operatorname{miR}-27 \mathrm{a}-3 \mathrm{p}$, were synthesized and inserted into the luciferase reporter plasmid (RiboBio). MCF-7 cells were seeded in 24-well plates, grown to $60 \%$ confluence, and co-transfected with plasmid plus miR-27a-3p mimics or miR-NC (RiboBio) using Lipo2000 (Invitrogen, Carlsbad, CA, USA). After $48 \mathrm{~h}$ of incubation, the luciferase activity was evaluated using the Dual-Luciferase Reporter Assay System (Promega, Madison city, WI, USA).

\section{Statistical Analysis}

Statistical analysis was performed with Graphpad Prism software 7.00. Data from triplicate experiments performed in a parallel manner were analyzed using Student's $t$-test or one-way analysis of variance (ANOVA). All values are expressed as mean $\pm \mathrm{SD}$. $P$ values $<0.05$ were considered statistically significant.

\section{Results}

\section{Differential Expressions of miR-27a-3p and MDRI in BC}

The miR-27a-3p expression data based on BC samples were screened from The Cancer Genome Atlas (TCGA). In 1083 tumors and 111 normal breast samples from TCGA database, the expression of miR-27a-3p was relatively higher in breast tumors than normal breast samples (Figure 1A). In 110 pairs of human BC tissues and adjacent normal tissues from TCGA database, relative miR27a-3p expression was higher in BC samples than adjacent normal samples (Figure 1B). The expression levels of miR-27a-3p and MDR1 were measured in MCF-7 and MCF-7/ADR cell lines by qRT-PCR and Western blot, respectively. The relative expression of miR-27a-3p was significantly higher (approximately 4-fold) in MCF-7/ ADR cells than in MCF-7 cells (Figure 1C). In addition, the expression level of MDR1 was obviously higher in the ADR-resistant MCF-7/ADR cells than in the parental MCF-7 cells (Figure 1D).

\section{miR-27a-3p Is Involved in ADR Resistance and Cell Proliferation}

To investigate the function of miR-27a-3p in drug resistance, miR-27a-3p mimics, miR-27a-3p inhibitors, and respective miR-NC were successfully transferred into MCF-7 and MCF-7/ADR cells, respectively. The expression of miR-27a-3p was higher in mimics-transfected MCF-7 cells than in miR-NC-transfected MCF-7 cells (Figure 2A). The expression of miR-27a-3p was lower in inhibitors-transfected MCF-7/ADR cells than in miR-NCtransfected MCF-7/ADR cells (Figure 2B). 
A

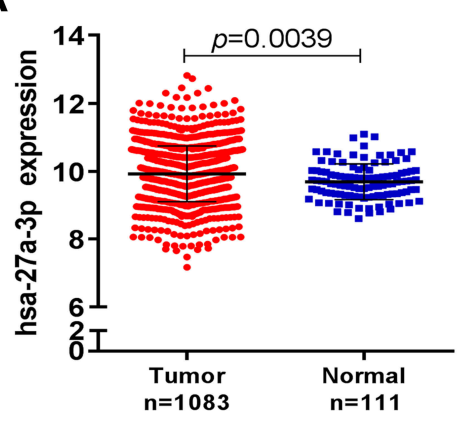

C

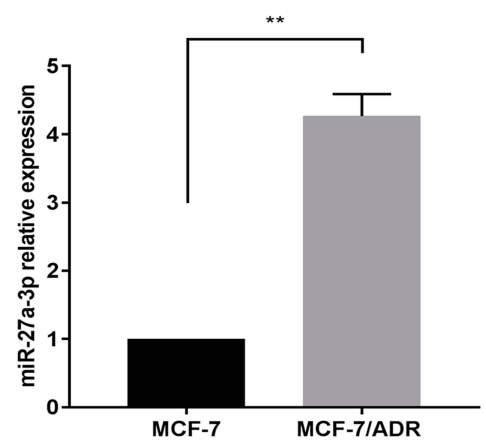

B

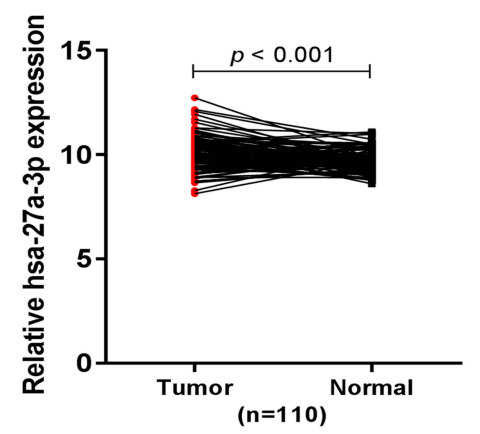

D

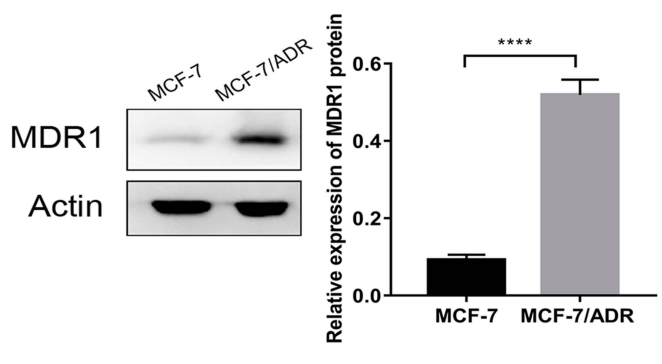

Figure I miR-27a-3p was up-regulated in BC tissues and ADR-resistant cell lines. (A) miR-27a-3p expression in I083 BC and III normal breast samples from TCGA database. (B) Expression levels of miR-27a-3p in 110 pairs of human BC tissues and adjacent normal tissues from TCGA database. (C) Expression levels of miR-27a-3p in MCF-7 cells and MCF-7/ADR cells based on qRT-PCR. (D) Expression levels of MDRI in MCF-7 cells and MCF-7/ADR cells based on Western blot analysis. **P < 0.01 ; $* * * * P<0.0001$. The data are expressed as mean \pm SD.

The sensitivity of MCF-7 and MCF-7/ADR cells to ADR was determined by CCK-8 assay. The IC50 values of ADR were $7.809 \pm 0.29 \mu \mathrm{M} / 1$ in MCF-7 cells and $116.3 \pm 0.98 \mu \mathrm{M} /$ 1 in MCF-7/ADR cells. MCF-7 cells transfected with miR27a-3p mimics had significantly decreased sensitivity to ADR when compared with cells transfected with miR-NC, as indicated by increased IC50 values (Figure 2C). Additionally, the IC50 values of ADR in MCF-7/ADR cells transfected with miR-27a-3p inhibitors were reduced significantly compared with the cells transfected with miR-NC (Figure 2D).

The CCK-8 assay also suggested that up-regulation of miR-27a-3p could induce MCF-7 cell growth, whereas down-regulation of miR-27a-3p in MCF-7/ADR cells suppressed proliferation (Figure 2E). The colony formation assay similarly demonstrated that promotion of miR-27a$3 p$ could have a positive effect on proliferation (Figure $2 \mathrm{~F}$ ), whereas inhibition of miR-27a-3p attenuated the effect (Figure 2F).

\section{Dysregulation of miR-27a-3p Is Associated with ADR-Induced Apoptosis}

To explore whether dysregulation of miR-27a-3p modulates ADR-induced apoptosis, we assessed the apoptosis rate of transfected cells at $48 \mathrm{~h}$ by flow cytometry assay.
We found that overexpression of miR-27a-3p reduced apoptosis in MCF-7 cells compared to the corresponding miR-NC, and underexpression of miR-27a-3p in MCF-7/ ADR cells induced the apoptosis rate (Figure 3A). Western blot demonstrated that miR-27a-3p suppression stimulated the expression of Bax and Cleaved-caspase3, and inhibited the expression of Bcl-2 and MDR1 (Figure 3B), whereas miR-27a-3p mimics decreased Bax and Cleaved-caspase 3 protein levels, and increased Bcl-2 and MDR1 protein levels (Figure 3B). In brief, the results indicated that dysregulation of miR-27a-3p could negatively regulate apoptosis in MCF-7 and MCF-7/ADR cells.

\section{miR-27a-3p Directly Targets BTG2 and Mediates BTG2 Expression Post-Translationally}

The practical experiments have demonstrated the essential role of miR-27a-3p in ADR-resistant BC, but the downstream targets of miR-27a-3p are still unknown. Through searching and filtering in miRNA bioinformatics prediction databases (miRWalk, TargetScan, PicTar, and StarBase v3.0), we identified BTG2 as a potential target gene of miR-27a-3p. In TCGA, BTG2 expression level 


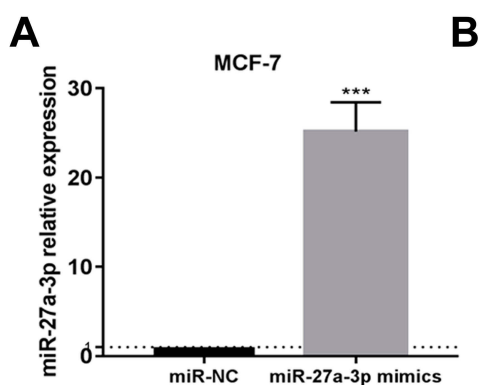

B
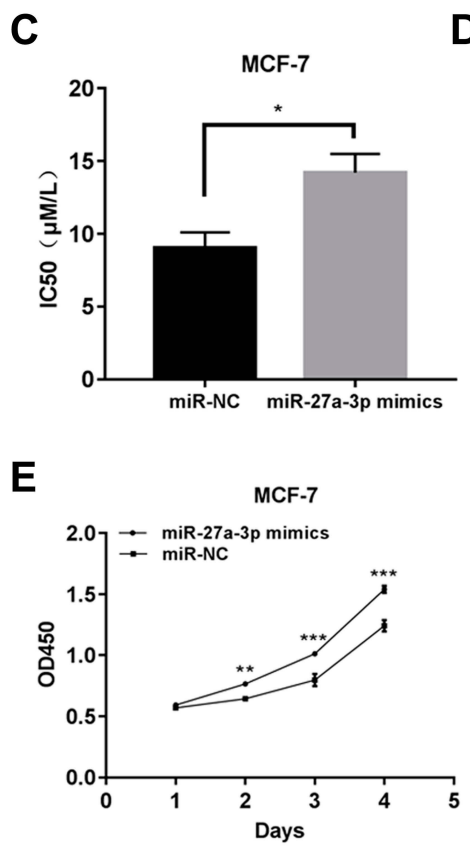

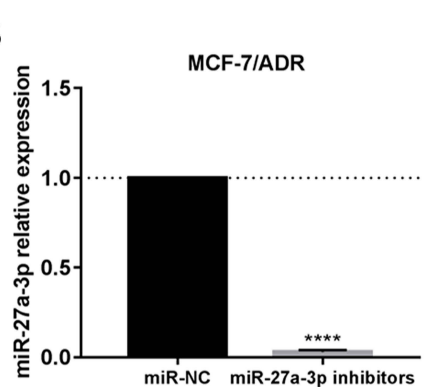

D
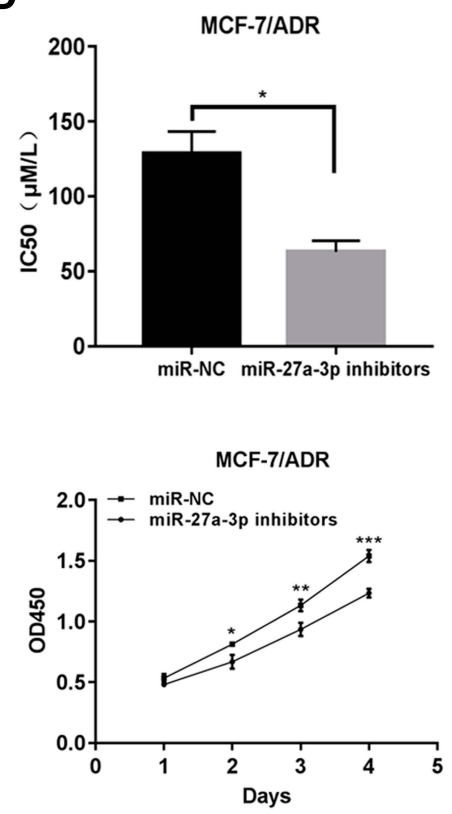

$\mathbf{F}$

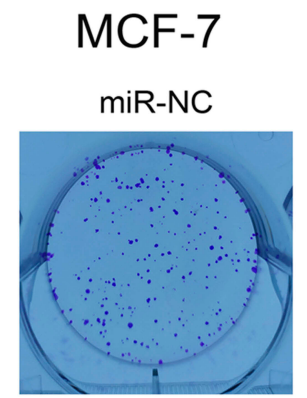

MCF-7/ADR

miR-NC

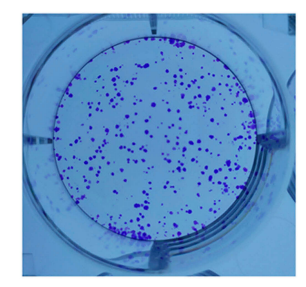

miR-27a-3p mimics

miR-27a-3p inhibitors

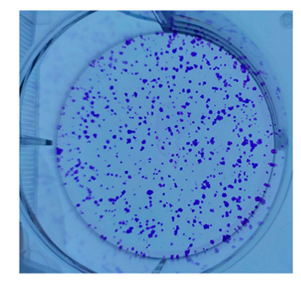

MCF-7

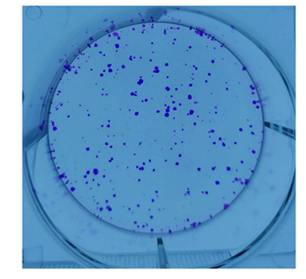

MCF-7IADR

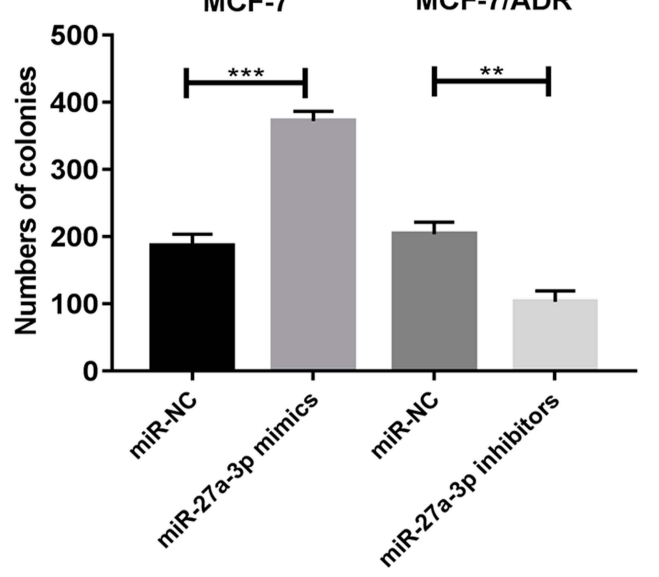

Figure 2 miR-27a-3p promoted proliferation and resistance of BC cells in vitro. (A and B) qRT-PCR was performed to examine miR-27a-3p expression in MCF-7 and MCF7/ADR cells transfected with either miR-27a-3p mimics or inhibitors. (C and D) IC50 was verified in MCF-7 and MCF-7/ADR cells transfected with either miR-27a-3p mimics or inhibitors. (E and F) Cell proliferation was determined with CCK-8 assays and colony formation assays in MCF-7 and MCF-7/ADR cells transfected with either miR-27a-3p mimics or inhibitors. $* P<0.05$; $* * P<0.01$; $* * * P<0.001$; $* * * * P<0.0001$. The data are expressed as mean \pm SD.

was negatively associated with the expression level of miR-27a-3p (Pearson's correlation, $r=-0.288$; Figure 4A). We also found that there is a highly complementary sequence in BTG2 mRNA 3'-UTR with miR-27a-3p (Figure 4B). A dual-luciferase reporter assay showed that miR-27a-3p mimics decreased the luciferase activity of wild reporters but did not affect reporters carrying the mutation binding sites in MCF-7 cells (Figure 4C).

To assess the connection between miR-27a-3p function and BTG2 expression, we performed Western blot and PCR analysis. Western blot demonstrated that the expression of BTG2 protein was lower in MCF-7 cells transfected with mimics than in those transfected with miR-NC, and was higher in MCF-7/ADR cells transfected with inhibitors than in those transfected with miR-NC (Figure 4D). Furthermore, qRT-PCR data demonstrated that the level of BTG2 mRNA decreased in MCF-7 cells transfected with miR-27a-3p mimics, and increased in MCF-7/ADR cells transfected with miR-27a-3p inhibitors (Figure 4E). These experiments indicated that BTG2 might be a direct target of miR$27 a-3 p$ and that its expression is inversely related to miR-27a-3p expression.

\section{BTG2 Reverses Cell Proliferation and Apoptosis of BC}

For further demonstration of the effect of BTG2 modulated by miR-27a-3p, BTG2 DNA sequence (BTG2) and siRNA 
A
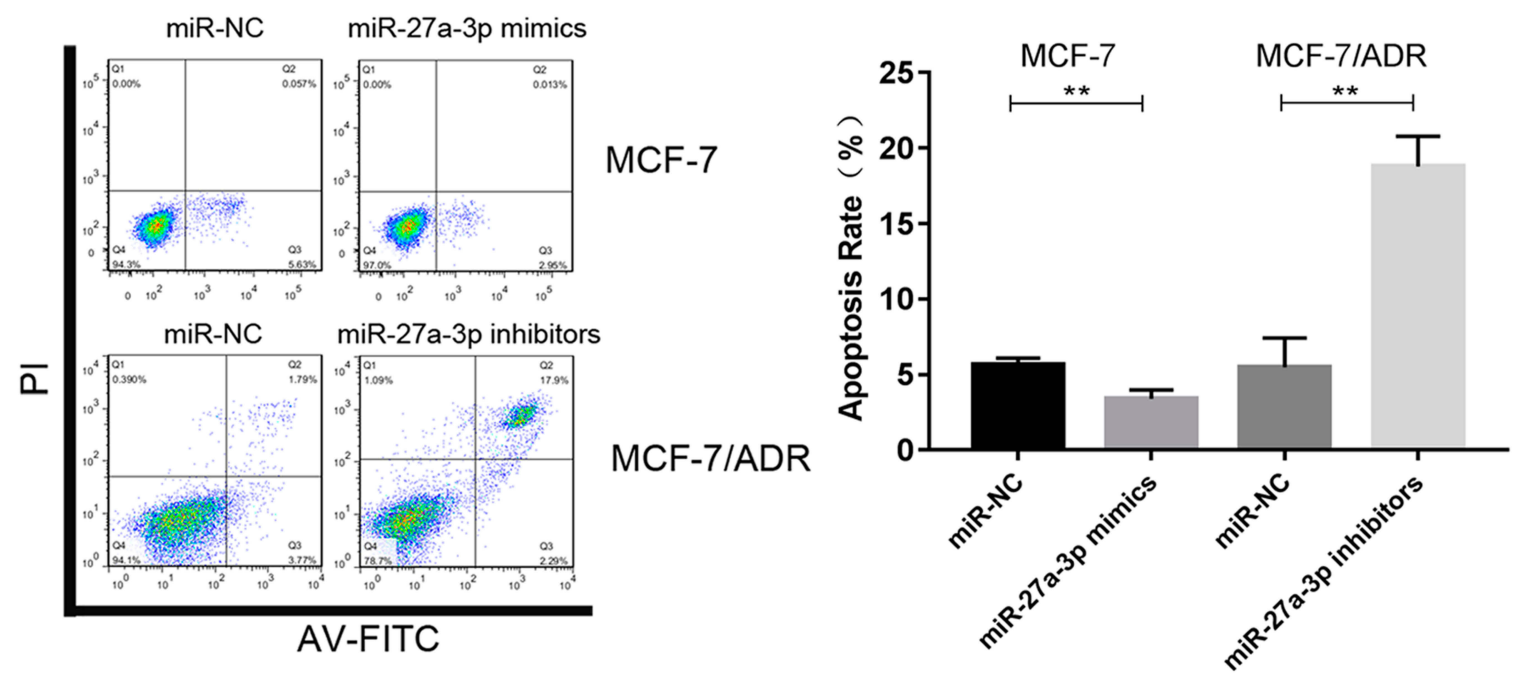

B

AV-FITC

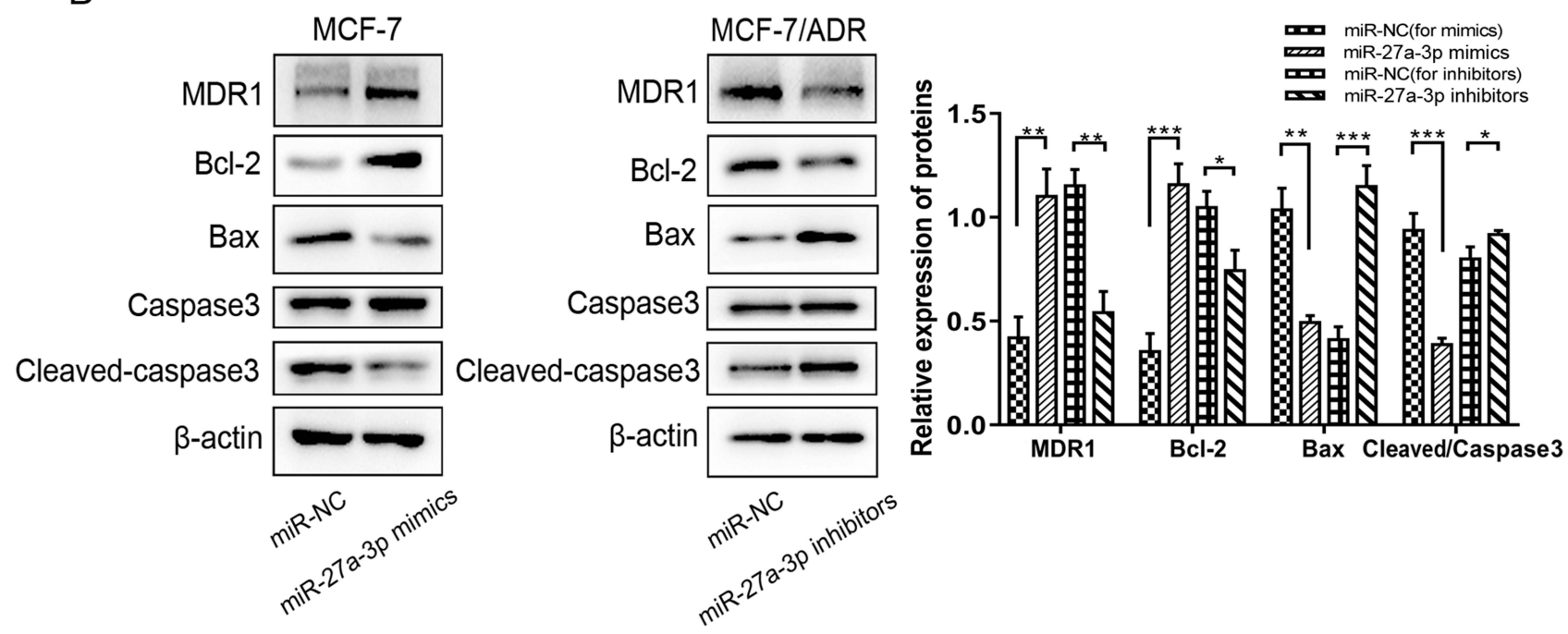

Figure 3 Dysregulation of miR-27a-3p is associated with ADR-induced apoptosis. (A) Flow cytometry analysis was analyzed in MCF-7 and MCF-7/ADR cells transfected with either miR-27a-3p mimics or inhibitors. (B) Western blot was performed to examine the effects of miR-27a-3p on apoptotic protein expression. Relative protein expression was normalized to $\beta$-actin. $* P<0.05$; $* * P<0.01$; *** $P<0.001$. The data are expressed as mean \pm SD.

(siBTG2) were transfected into MCF-7 and MCF-7/ADR cells at a stable concentration $(50 \mathrm{nM} / \mathrm{L})$, respectively. BTG2 in these transfected cell lines markedly reversed the protein expression levels (Figure 5A), indicating that the transfection of BTG2 is effective. CCK-8 assay and colony formation assay demonstrated that BTG2 partially reversed the effects on cell growth produced by miR-27a-3p mimics/ inhibitors, and these effects were still present at $96 \mathrm{~h}$ after transfection (Figure 5B and C). Next, we analyzed the apoptosis of transfected cells after regulation of BTG2. We found that BTG2 could enhance ADR-induced apoptosis and expression of Bax and Cleaved-caspase- 3 protein in MCF-7 cells transfected with miR-27a-3p mimics, while siBTG2 demonstrated the opposite effects in MCF-7/ADR cells transfected with miR-27a-3p inhibitors (Figure 6A and $\mathrm{B}$ ). These results verified that BTG2 is involved in the regulation of cell apoptosis in $\mathrm{BC}$.

\section{miR-27a-3p Increases the Activation of the PI3K/Akt Pathway by Targeting BTG2}

Based on the above, we were able to clarify the effect of miR27a-3p on BTG2 in ADR-resistant cells. To explore the mechanisms of miR-27a-3p and BTG2, we performed Western blot analysis to assess the expression of Akt and p-Akt protein in downstream pathways. In treatment with miR-27a-3p mimics or miR-NC in MCF-7 cells, the expression of p-Akt protein was strongly up-regulated (Figure 6B); in treatment with miR-27a-3p inhibitors or miR-NC, the level 
A

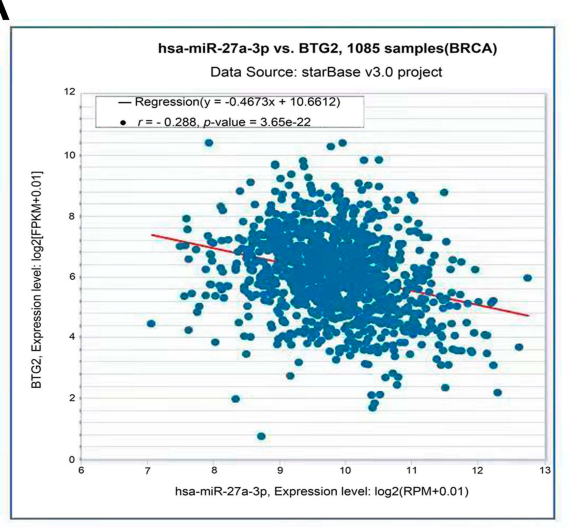

C

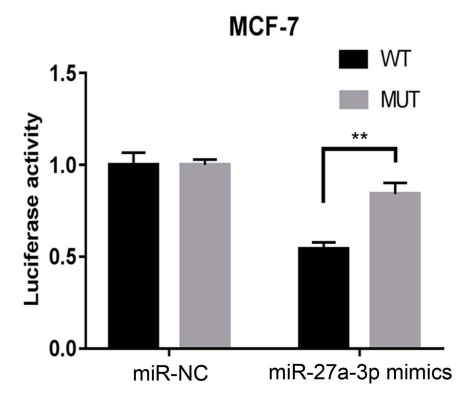

$\mathbf{E}$

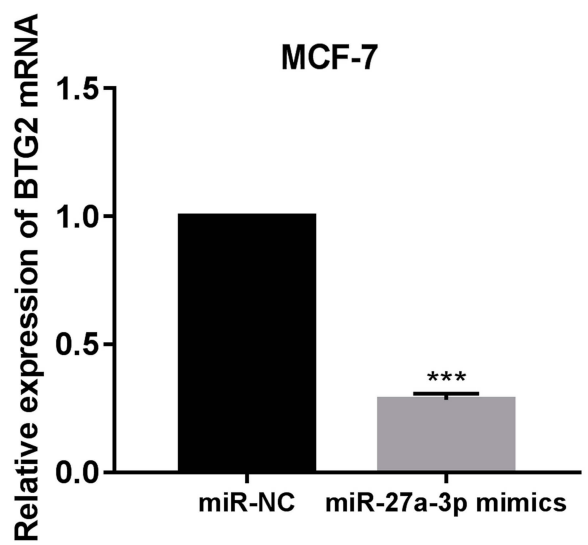

B

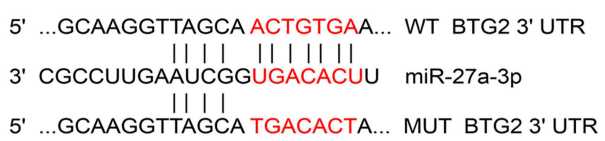
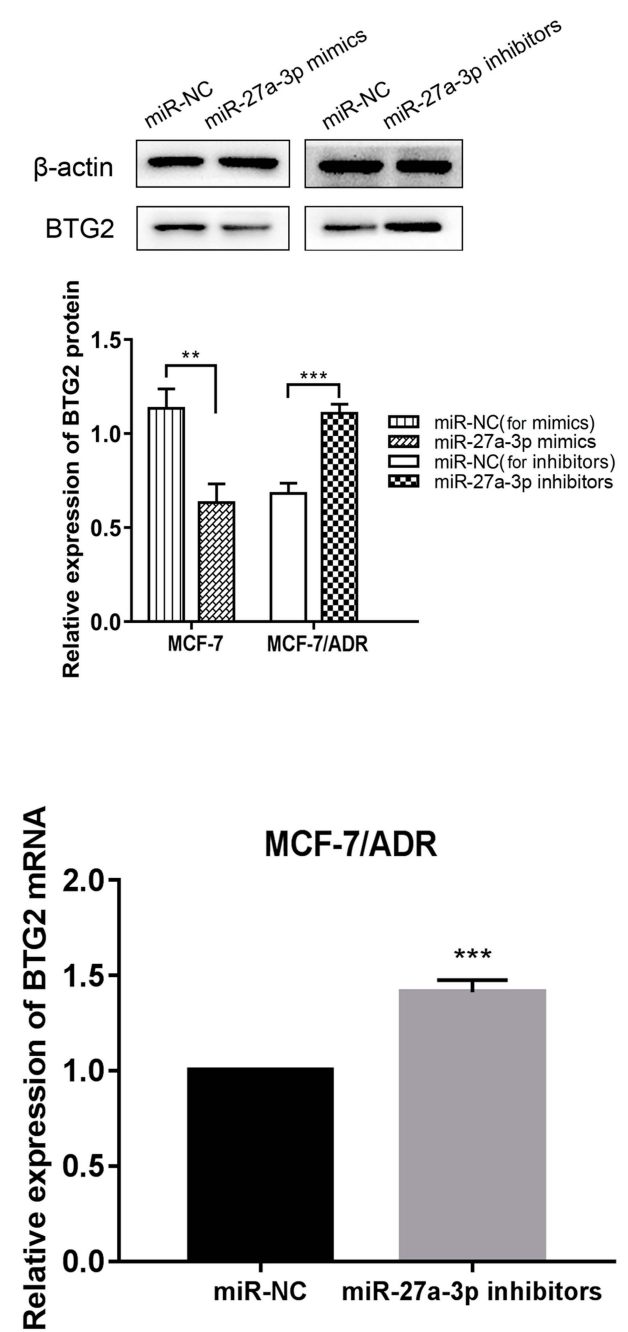

Figure 4 miR-27a-3p directly targeted BTG2 and regulated its expression in BC cells. (A) A negative correlation was seen between the expression levels of miR-27a-3p and BTG2 in BC specimens from TCGA $(r=-0.288$; $P<0.05)$. (B) The seed sequence of miR-27a-3p is complementary to the 3'UTR of BTG2. (C) Luciferase activity was analyzed in MCF-7 cells transfected with miR-27a-3p mimics and miR-NC. (D) Western blot analysis demonstrated levels of BTG2 protein in MCF-7 and MCF-7/ADR cells transfected with miR-27a-3p mimics or inhibitors. (E) qRT-PCR was performed to examine the relative expression of BTG2 mRNA in MCF-7 and MCF-7/ADR cells transfected with miR-27a-3p mimics or inhibitors. $* * P<0.01$; *** $P<0.001$. The data are expressed as mean \pm SD.

of p-Akt protein was down-regulated. Moreover, both BTG2 overexpression in the MCF-7 cells and BTG2 knockdown in the MCF-7/ADR cells reversed the p-Akt expression levels. In short, the experiments suggested that miR-27a-3p activated the PI3K/Akt pathway by targeting BTG2.

\section{Discussion}

ADR plays an important role in chemotherapy for patients with BC. However, the occurrence of drug resistance can block the efficacy of this treatment, resulting in severe restrictions on its clinical use. Previous research has established that miR-27a-3p is implicated in the biological behavior of tumor cells in numerous cancer types. ${ }^{29-31}$ Although research has also suggested that changes in miR-27a-3p expression are associated with the chemosensitivity of various malignancies, ${ }^{32-34}$ the specific role that miR-27a-3p plays in the regulation of $\mathrm{ADR}$ resistance in $\mathrm{BC}$ has not been well established. Further research regarding the 
A
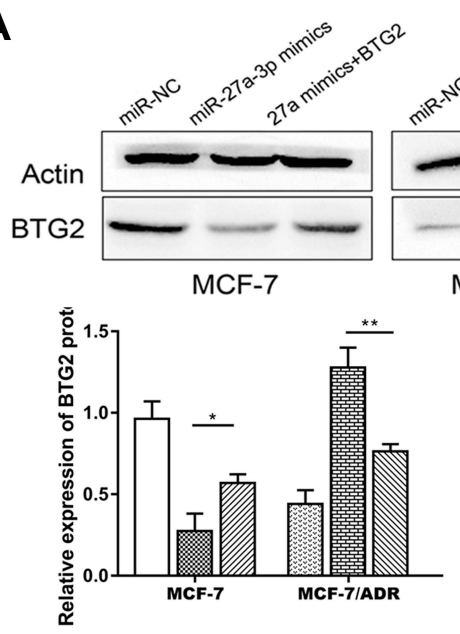

B

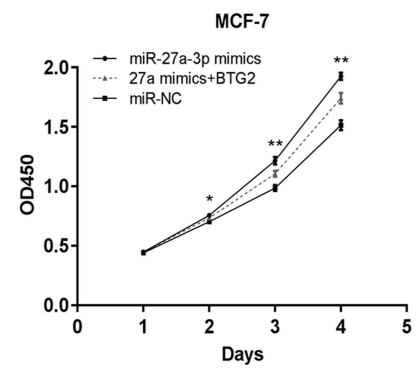

MCF-7/ADR

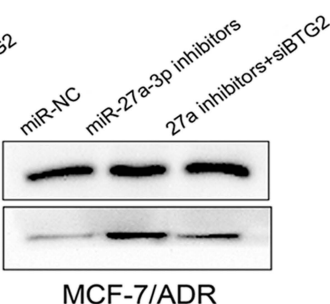

$$
\begin{aligned}
& \text { miR-NC(for mimics) } \\
& \text { miR-27a-3p mimics } \\
& 27 a \text { mimics+BTG2 } \\
& \text { miR-NC(for inhibitors) } \\
& \text { miR-27a-3p inhibitors } \\
& 27 a \text { inhibitors+siBTG2 }
\end{aligned}
$$

C
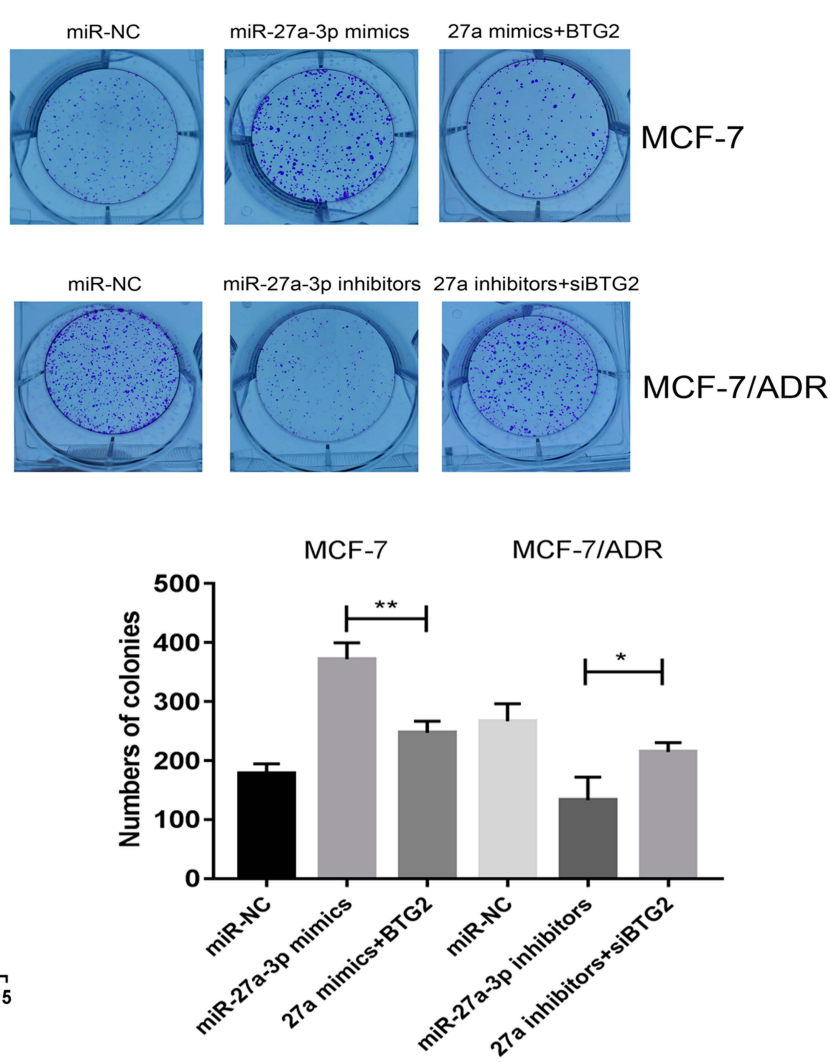

Figure 5 BTG2 reversed the effects of miR-27a-3p in BC cell proliferation. (A) The levels of BTG2 protein expression were measured by Western blot analysis. (B and C) CCK-8 and colony formation assays were used to assess cell proliferation in MCF-7 and MCF-7/ADR cells transfected with miR-27a-3p mimics, miR-27a-3p inhibitors, 27a$3 p$ mimics+BTG2, 27a-3p inhibitors + siBTG2 and corresponding miR-NC. $* P<0.05 ; * * p<0.01$; $* * * P<0.001$. The data are expressed as mean \pm SD.

mechanisms of ADR resistance are needed so that effective agents can be developed to reverse chemoresistance.

Several studies have shown that the up-regulation of miR$27 \mathrm{a}-3 \mathrm{p}$ promotes cancer chemoresistance in some malignancies such as gastric carcinoma ${ }^{35}$ and ovarian carcinoma. ${ }^{17}$ In contrast, other studies have found that miR-27a-3p serves as an inhibitor in drug resistance for certain tumors such as leukemia $^{16}$ and hepatocellular carcinoma. ${ }^{15}$ In this study, we sought to clarify the potential correlation between miR-27a-3p and chemoresistance in $\mathrm{BC}$. We found that miR-27a-3p had a positive correlation with ADR resistance in $\mathrm{BC}$ cells. More specifically, we observed that significantly higher expression of miR-27a-3p in the MCF-7/ADR cell line versus in the MCF-7 cell line was accompanied by increased expression of MDR1 protein. Furthermore, the sensitivity of MCF-7/ADR cells was elevated after transfection with inhibitors of miR27a-3p, whereas the MCF-7 cell line demonstrated decreased sensitivity to ADR after treatment with mimics. Inhibitors of miR-27a-3p restrained MCF-7/ADR cell proliferation and promoted ADR-induced apoptosis in vitro, and the opposite effects were seen with mimics of miR-27a-3p. Taken together, these findings suggest the importance of miR-27a-3p in ADR resistance.

As a tumor suppressor, BTG2 is expressed at low levels in $\mathrm{BC}$ and is recognized as a regulator of tumor size, metastasis, recurrence, and overall survival. ${ }^{27,36}$ However, the association between BTG2 function and miR-27a-3p in ADR-resistant BC was previously poorly understood. In this study, we found that BTG2 was a direct target of miR-27a-3p. A dual-luciferase reporter assay demonstrated that miR-27a-3p down-regulated BTG2 expression by binding to the 3'UTR of BTG2 mRNA. Further research demonstrated that BTG2 reduced the effect of miR-27a-3p inhibitors/mimics. Our results also suggested the presence of an axis between miR-27a-3p and BTG2 that regulates the chemoresistance of BC cells through the PI3K/Akt signaling pathway. The PI3K/Akt signaling pathway has been found to be suppressed by BTG2 in many types of malignancies. ${ }^{37,38}$ Our data showed that miR-27a-3p mimics enhanced the expression of the signaling pathway, and BTG2 up-regulation partially overcame this promoted expression. 
A
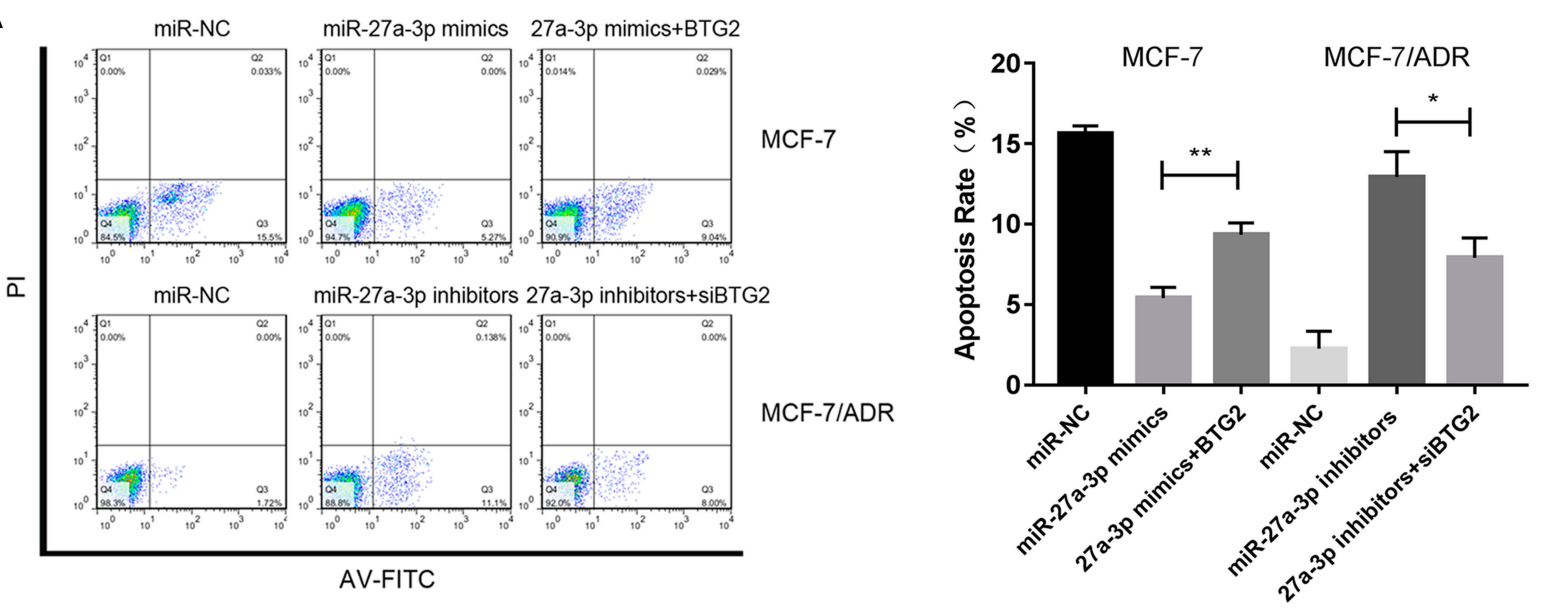

B

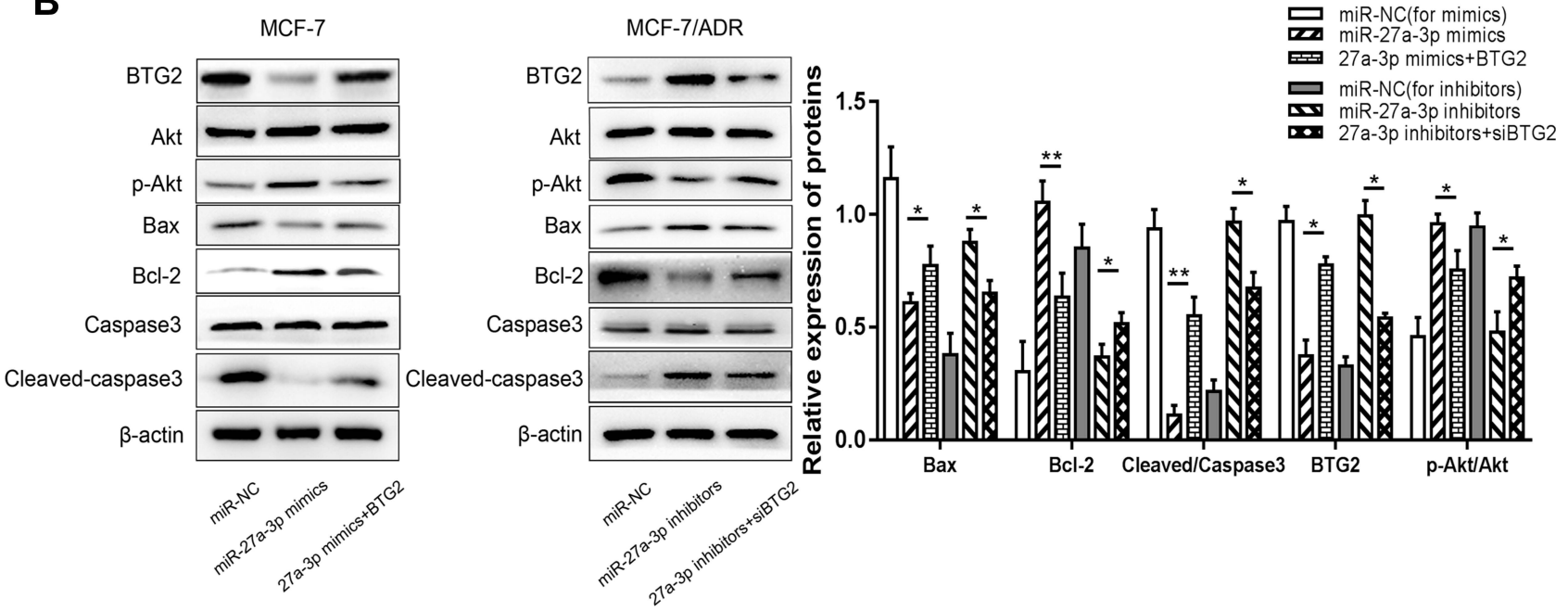

Figure 6 BTG2 reversed the effects of miR-27a-3p in cell apoptosis of BC, and the PI3K/Akt signaling pathway was a potential downstream target of miR-27a-3p/BTG2. (A) Flow cytometry analysis was used to measure apoptosis of MCF-7 and MCF-7/ADR cells transfected with miR-27a-3p mimics, miR-27a-3p inhibitors, 27a-3p mimics+BTG2, 27a-3p inhibitors+siBTG2 and corresponding miR-NC. (B) Western blot analysis was used to assess BTG2, Akt, p-Akt, Bax, Bcl-2, Caspase3, and Cleaved-caspase3 in MCF7 and MCF-7/ADR cells transfected with miR-27a-3p mimics, miR-27a-3p inhibitors, 27a-3p mimics+BTG2, 27a-3p inhibitors+siBTG2 and corresponding miR-NC. Relative protein expression was normalized to $\beta$-actin. $* P<0.05$; $* * P<0.01$. The data are expressed as mean \pm SD.

Overall, these results suggest that miR-27a-3p activates the PI3K/Akt signaling pathway by targeting BTG2 in MCF7/ADR cells. These early findings may provide a starting point in developing a promising therapeutic strategy for overcoming chemoresistance. Recently, results from miRNA and siRNA studies have been applied clinically, with researchers applying these findings to targeted therapy for BC, gene editing, and early screening for cancer. ${ }^{39}$ The potential clinical value of miR-27a-3p in overcoming resistance to chemotherapy is also well worth pursuing. This study identified the role of miR-27a-3p and its target gene BTG2 in BC resistance, but insufficiency still exists.

The present work has several limitations. Expression of miR-27a-3p, is positively correlated with p-Akt protein level, but the detailed mechanism underlying this regulation remained unclear. Further investigations are still needed to clarify the mechanisms underlying this activation. Moreover, the effect of miR-27a-3p on chemoresistance of BC has not been verified in animal experiments, so it is not clear whether miR-27a-3p affects the volume of ADRresistant tumor and the metastasis of the tumor in the lungs and the livers. We are also collecting clinical specimens to verify the expression of miR-27a-3p and BTG2.

\section{Conclusion}

In summary, our study demonstrates that miR-27a-3p participates in reversing drug resistance positively via regulating BTG2. The function of miR-27a-3p in breast cancer cell 
chemo-sensitivity and apoptosis was mediated by targeting BTG2 and subsequently promoting activation of PI3K/Akt signaling pathway.

\section{Data Sharing Statement}

The datasets used and analyzed during the current study are available from the corresponding author on reasonable request.

\section{Funding}

This present work was kindly supported by the Social Development Foundation of Science and Technology of Jiangsu (No. BE2016658), the Changzhou Sci \& Tech Program (No.CE20165020), the High-Level Medical Talents Training Project of Changzhou (No.2016CZLJ007), the Project of Changzhou medical innovation team (No. CCX201807), grants from the Natural Science Foundation of China (81702591), and the Natural Science Foundation of Jiangsu Province (BK20170294).

\section{Disclosure}

The authors declare that they have no conflicts of interest.

\section{References}

1. Ferlay J, Colombet M, Soerjomataram I, et al. Estimating the global cancer incidence and mortality in 2018: GLOBOCAN sources and methods. Int $J$ Cancer. 2019;144(8):1941-1953. doi:10.1002/ijc.31 937

2. Gradishar WJ, Anderson BO, Balassanian R, et al. Breast cancer, version 4.2017, NCCN clinical practice guidelines in oncology. J Natl Compr Canc Netw. 2018;16(3):310-320. doi:10.6004/jncen.2018.0012

3. Cai F, Luis MAF, Lin X, et al. Anthracycline-induced cardiotoxicity in the chemotherapy treatment of breast cancer: preventive strategies and treatment. Mol Clin Oncol. 2019;11(1):15-23. doi:10.3892/mco.20 19.1854

4. Gabizon AA, Patil Y, La-Beck NM. New insights and evolving role of pegylated liposomal doxorubicin in cancer therapy. Drug Resist Updat. 2016;29(1):90-106. doi:10.1016/j.drup.2016.10.003

5. Rivera E. Liposomal anthracyclines in metastatic breast cancer: clinical update. Oncologist. 2003;8(suppl 2):3-9. doi:10.1634/theoncologist.8suppl_2-3

6. Hassan MS, Ansari J, Spooner D, Hussain SA. Chemotherapy for breast cancer. Oncol Rep. 2010;24(5):1121-1131. doi:10.3892/or 00000963

7. $\mathrm{Pu} \mathrm{M}$, Chen J, Tao Z, et al. Regulatory network of miRNA on its target: coordination between transcriptional and post-transcriptional regulation of gene expression. Cell Mol Life Sci. 2019;76(3):4 41-451. doi:10.1007/s00018-018-2940-7

8. Formosa A, Markert EK, Lena AM, et al. MicroRNAs, miR-154, miR-299-5p, miR-376a, miR-376c, miR-377, miR-381, miR-487b, miR-485-3p, miR-495 and miR-654-3p, mapped to the $14 q 32.31$ locus, regulate proliferation, apoptosis, migration and invasion in metastatic prostate cancer cells. Oncogene. 2014;33(44):5173-5182. doi:10.1038/onc.2013.451

9. Pan BL, Tong ZW, Wu L, et al. Effects of microRNA-206 on osteosarcoma cell proliferation, apoptosis, migration and invasion by targeting ANXA2 through the AKT signaling pathway. Yonsei Med J. 2018;45(4):1410-1422.
10. Zhou Y, Li S, Li J, Wang D, Li Q. Effect of microRNA-135a on cell proliferation, migration, invasion, apoptosis and tumor angiogenesis through the IGF-1/PI3K/Akt signaling pathway in non-small cell lung cancer. Cell Physiol Biochem. 2017;42(4):1431-1446. doi:10.1159/ 000479207

11. Kim SY, Kim AY, Lee HW, et al. miR-27a is a negative regulator of adipocyte differentiation via suppressing PPAR $\gamma$ expression. Biochem Biophys Res Commun. 2010;392(3):323-328. doi:10.1016/j.bbrc.20 10.01 .012

12. Mu Y, Zhang L, Chen X, Chen S, Shi Y, Li J. Silencing microRNA27a inhibits proliferation and invasion of human osteosarcoma cells through the SFRP1-dependent Wnt/ $\beta$-catenin signaling pathway. Biosci Rep. 2019;39(6):BSR20182366. doi:10.1042/BSR20182366

13. Xu CL, Cheng H, Li N, Zhou N, Tang XS. Relationship between microRNA-27a and efficacy of neoadjuvant chemotherapy in gastric cancer and its mechanism in gastric cancer cell growth and metastasis. Biosci Rep. 2019;39(5):BSR20181175. doi:10.1042/BSR 20181175

14. Su C, Huang DP, Liu JW, Liu WY, Cao YO. miR-27a-3p regulates proliferation and apoptosis of colon cancer cells by potentially targeting BTG1. Oncol Lett. 2019;18(3):2825-2834. doi:10.3892/ol.2019. 10629

15. Chen Z, Ma T, Huang C, et al. MiR-27a modulates the MDR1/ P-glycoprotein expression by inhibiting FZD7/ $\beta$-catenin pathway in hepatocellular carcinoma cells. Cell Signal. 2013;25(12):2693-2701. doi:10.1016/j.cellsig.2013.08.032

16. Feng DD, Zhang H, Zhang P, et al. Down-regulated miR-331-5p and miR-27a are associated with chemotherapy resistance and relapse in leukaemia. J Cell Mol Med. 2011;15(10):2164-2175. doi:10.1111/ j.1582-4934.2010.01213.x

17. Li Z, Hu S, Wang J, et al. MiR-27a modulates MDR1/P-glycoprotein expression by targeting HIPK2 in human ovarian cancer cells. Gynecol Oncol. 2010;119(1):125-130. doi:10.1016/j.ygyno.2010. 06.004

18. Kong LY, Xue M, Zhang QC, Su CF. In vivo and in vitro effects of microRNA-27a on proliferation, migration and invasion of breast cancer cells through targeting of SFRP1 gene via Wnt $/ \beta$-catenin signaling pathway. Oncotarget. 2017;8(9):15507-15519. doi:10.186 32/oncotarget.14662

19. Tang W, Yu F, Yao H, et al. miR-27a regulates endothelial differentiation of breast cancer stem like cells. Oncogene. 2014;33 (20):2629-2638. doi:10.1038/onc.2013.214

20. Ren YQ, Fu F, Han J. MiR-27a modulates radiosensitivity of triple-negative breast cancer (TNBC) cells by targeting CDC27. Med Sci Monit. 2015;21:1297-1303. doi:10.12659/MSM.893974

21. Ljepoja B, García-Roman J, Sommer AK, Wagner E, Roidl A. MiRNA-27a sensitizes breast cancer cells to treatment with selective estrogen receptor modulators. Breast. 2019;43:31-38. doi:10.1016/j. breast.2018.10.007

22. Zhou S, Huang Q, Zheng S, Lin K, You J, Zhang X. miR-27a regulates the sensitivity of breast cancer cells to cisplatin treatment via BAK-SMAC/DIABLO-XIAP axis. Tumour Biol. 2016;37 (5):6837-6845. doi:10.1007/s13277-015-4500-1

23. Winkler GS. The mammalian anti-proliferative BTG/Tob protein family. J Cell Physiol. 2010;222(1):66-72. doi:10.1002/jcp.21919

24. Tsui KH, Chiang KC, Lin YH, Chang KS, Feng TH, Juang HH. BTG2 is a tumor suppressor gene upregulated by p53 and PTEN in human bladder carcinoma cells. Cancer Med. 2018;7(1):184-195. doi: $10.1002 /$ cam 4.1263

25. Wei S, Hao C, Li X, Zhao H, Chen J, Zhou Q. Effects of BTG2 on proliferation inhibition and anti-invasion in human lung cancer cells. Tumor Biol. 2012;33(4):1223-1230. doi:10.1007/s13277-012-0370-y

26. Zhang YJ, Wei L, Liu M, et al. BTG2 inhibits the proliferation, invasion, and apoptosis of MDA-MB-231 triple-negative breast cancer cells. Tumor Biol. 2013;34(3):1605-1613. doi:10.1007/s13277013-0691-5 
27. Möllerström E, Kovács A, Lövgren K, et al. Up-regulation of cell cycle arrest protein BTG2 correlates with increased overall survival in breast cancer, as detected by immunohistochemistry using tissue microarray. BMC Cancer. 2010;10(1):296-307. doi:10.1186/14712407-10-296

28. Frampton AE, Castellano L, Colombo T, et al. Integrated molecular analysis to investigate the role of microRNAs in pancreatic tumour growth and progression. Lancet. 2015;385(4):S37. doi:10.1016/S014 0-6736(15)60352-X

29. Chae DK, Ban E, Yoo YS, Kim EE, Baik JH, Song EJ. MIR-27a regulates the TGF- $\beta$ signaling pathway by targeting SMAD2 and SMAD4 in lung cancer. Mol Carcinog. 2017;56(8):1992-1998. doi: $10.1002 / \mathrm{mc} .22655$

30. Liu X, Pan B, Sun L, et al. Circulating exosomal miR-27a and miR-130a act as novel diagnostic and prognostic biomarkers of colorectal cancer. Cancer Epidemiol Biomarkers Prev. 2018;27(7):74 6-754. doi:10.1158/1055-9965.EPI-18-0067

31. Zhang LY, Chen Y, Jia J, Zhu X, He Y, Wu LM. MiR-27a promotes EMT in ovarian cancer through active Wnt/ $\beta$-catenin signalling by targeting FOXO1. Cancer Biomark. 2019;24(1):31-42. doi:10.3233/ CBM-181229

32. Li J, Wang Y, Song Y, Fu Z, Yu W. miR-27a regulates cisplatin resistance and metastasis by targeting RKIP in human lung adenocarcinoma cells. Mol Cancer. 2014;13(1):193-202. doi:10.1186/ 1476-4598-13-193
33. Danza K, Silvestris N, Simone G, et al. Role of miR-27a, miR-181a and miR-20b in gastric cancer hypoxia-induced chemoresistance. Cancer Biol Ther. 2016;17(4):400-406. doi:10.1080/15384047.2016.1139244

34. Cao Z, Xu L, Zhao S. Exosome-derived miR-27a produced by PSC-27 cells contributes to prostate cancer chemoresistance through p53. Biochem Biophys Res Commun. 2019;515(2):345-351. doi:10. 1016/j.bbrc.2019.05.120

35. Zhao X, Yang L, Hu J. Down-regulation of miR-27a might inhibit proliferation and drug resistance of gastric cancer cells. J Exp Clin Cancer Res. 2011;30(1):55-60. doi:10.1186/1756-9966-30-55

36. Kawakubo H, Carey JL, Brachtel E, et al. Expression of the NF$\kappa \mathrm{B}$-responsive gene BTG2 is aberrantly regulated in breast cancer. Oncogene. 2004;23(50):8310-8319. doi:10.1038/sj.onc.1208008

37. Li YJ, Dong BK, Fan M, Jiang WX. BTG2 inhibits the proliferation and metastasis of osteosarcoma cells by suppressing the PI3K/AKT pathway. Int J Clin Exp Pathol. 2015;8(10):12410-12418.

38. Sundaramoorthy S, Ryu MS, Lim IK. B-cell translocation gene 2 mediates crosstalk between $\mathrm{PI} 3 \mathrm{~K} / \mathrm{Akt}$ and $\mathrm{NF \kappa B}$ pathways which enhances transcription of MnSOD by accelerating I $\kappa \mathrm{B} \alpha$ degradation in normal and cancer cells. Cell Commun Signal. 2013;11(1):69-83. doi:10.1186/1478-811X-11-69

39. Catela Ivkovic T, Voss G, Cornella H, Ceder Y. microRNAs as cancer therapeutics: a step closer to clinical application. Cancer Lett. 2017;407(1):113-122. doi:10.1016/j.canlet.2017.04.007

\section{Publish your work in this journal}

OncoTargets and Therapy is an international, peer-reviewed, open access journal focusing on the pathological basis of all cancers, potential targets for therapy and treatment protocols employed to improve the management of cancer patients. The journal also focuses on the impact of management programs and new therapeutic agents and protocols on patient perspectives such as quality of life, adherence and satisfaction. The manuscript management system is completely online and includes a very quick and fair peer-review system, which is all easy to use. Visit http://www.dovepress.com/ testimonials.php to read real quotes from published authors. 